Ciudad y territorio 


\section{Gentrificación estratégica}

\section{Dra. Otilia Beatriz Fiori Arantes, Filósofa}

Invitada internacional

Facultad de Arquitectura y Urbanismo. Universidad Católica de São Paulo.

otiliabfa@uol.com.br

Traducción del portugués por MSc. Ana Paula Montes, Arquitecta

Profesora

Escuela de Arquitectura de la Universidad de Costa Rica.

anapaula.montes@gmail.com

Recibido: julio del 2015

Aceptado: febrero del 2016

Ciudad y territorio

Ensayo 


\section{Resumen}

Para la Revista de Arquitectura de la Universidad de Costa Rica es un honor presentar una traducción al español de este artículo que fue originalmente publicado en portugués en Berlim e Barcelona. Duas imagens estratégicas. São Paulo: Annablume, $1^{\text {a }}$ edição, 2012, pp. 13-26 bajo el título "Gentrificação Estratégica".

Este ensayo aborda la discusión en torno al énfasis superlativo que asume la industria cultural en la incorporación de la ciudad a la transnacionalización productiva y financiera. Se argumenta que, desde el discurso de la cultura, se justifica la utilización de una jerga de civilidad, (doctrina punitiva), dentro del conjunto de prácticas de revalorización urbana y planificación estratégica, (gentrificación - privatización) bajo la promesa de crecimiento, empleo y negocios y el objetivo de cristalizar aquella imagen mítica del rentable bienestar de la ultra modernidad. Para esto, los ejemplos arquetípicos (Barcelona, París, Lisboa, Bilbao, Boston, Manhattan y Baltimore) sirven para ilustrar la noción de ciudad comprendida como una máquina de crecimiento.

Palabras clave: industria cultural; gentrificación; máquina de crecimiento; planeamiento estratégico.

\section{Abstract}

For the Journal of Architecture of the University of Costa Rica is an honor to present a spanish translation of the article "Gentrificação Estratégica" that was published in portuguese in Berlim e Barcelona. Duas imagens estratégicas. São Paulo: Annablume, $1^{a}$ edição, 2012, pp. 13-26.

This essay discusses the superlative emphasis assumed by the cultural industry in incorporating the city into productive and financial transnationalization. It is argued that through the discourse on culture, the vocabulary of civility is justified and incorporated into the set of practices of urban regeneration and strategic planning (gentrification - privatization) under the promise of growing employment and businesses which crystallize the mythical image of profitable ultra modernity. In doing so, archetypal examples (Barcelona, Paris, Lisbon, Bilbao, Boston, Manhattan, Baltimore) serve to illustrate the notion of city understood as a growth machine.

Keywords: cultural industry; gentrification; growth machine; strategic planning. 


\title{
Gentrificación estratégica
}

\author{
Otilia Beatriz Fiori Arantes ${ }^{1}$ \\ Traducción de Ana Paula Montes²
}

\section{Introducción}

A pesar de que las exposiciones y los concursos internacionales ven frustradas sus expectativas en cuanto al público que un evento de tal magnitud con toda su parafernalia debería estar atrayendo, o en cuanto a las ventajas económicas y geopolíticas que pudieran derivarse de éstas, los logros como los Juegos Olímpicos en Barcelona, los Grandes Proyectos Parisinos 3 , especialmente en la década de los años 80, o incluso el exuberante Museo de Bilbao (que finalmente elevó al arquitecto Frank Gehry a los cielos del star system) parecen ofrecer hoy en día la formula mágica para hacer ciudades.

Valiéndome de una expresión de Francesco Indovina - "ciudades ocasionales" - tuve la oportunidad de observar, refiriéndome particularmente a la Expo 98 de Lisboa 4 que no importa si se trata de los Juegos Olímpicos, la Copa del Mundo, la exhibición de esto o aquello, una catástrofe natural, 200 años de la Revolución Francesa, 500 años del descubrimiento de América o de Brasil, o incluso la sala de exhibición de un museo extravagante, lo importante es saber que millones de personas y metros cúbicos de tierra serán removidos. Siempre que implique gastos y salarios en especie, da lo mismo abrir y cerrar agujeros de dimensiones faraónicas, o construir pirámides y otros prismas espectrales, en los que se cristalice la imagen mítica del rentable bienestar

\footnotetext{
1 Licenciada en Filosofía por la Universidad Federal de Río Grande del Sur (1961), máster en Filosofía por la Universidad de São Paulo (1968), doctorado en Filosofía - Universidad de París I (Panthéon - Sorbonne) (1972) y la habilitación de la Universidad de Sao Paulo (1992). Imparte cursos en la Universidad Católica de São Paulo, en la Facultad de Arquitectura y Urbanismo y el Departamento de Filosofía de la Universidad de São Paulo, de la que se retiró en 1993. Presidió el Centro de Estudios de Arte Contemporáneo (1979-1992). Tiene experiencia en el área de Filosofía, con énfasis en Estética, principalmente en los siguientes temas: modernidad, la posmodernidad, Mario Pedrosa, crítica de arte en Brasil, arte y la política; arquitectura y urbanismo. (Nota de la traductora).

2 Ana Paula Montes arquitecta (2003) por la Universidad de Costa Rica (UCR) y Máster en Urbanismo (2010) por la Universidad Politécnica de Cataluña, España (UPC). Cuenta con 12 años de experiencia profesional y 5 años de experiencia académica universitaria. Actualmente trabaja como docente en la Escuela de Arquitectura y Urbanismo del Instituto Tecnológico de Costa Rica, en la Escuela de Arte y Comunicación Visual de la Universidad Nacional y en la Escuela de Arquitectura de la UCR. Es co-editora de la Revista de Arquitectura de la Universidad de Costa Rica. Desarrolla las siguientes líneas de Investigación: Historia de la Arquitectura; Teoría Urbana; Antropología y Etnografía Urbana; Estudios Culturales.

3 François Mitterrand experimentó en la década de los años 80’s con una serie de proyectos urbano - arquitectónicos que operaron para transformar la ciudad de París en un monumento. Entre estos proyectos se encuentran el Museo de Orsay (1986), Instituto del Mundo Árabe (1987), Ópera Bastilla (1989), la Pirámide del Louvre (1989), Gran Arco de La Défense (1989) y la Biblioteca Nacional de Francia (1988). (Nota de la traductora).

4 Cf. Vendo Cidades, en Veredas n 36, Río de Janeiro, diciembre, 1998, pp. 21-23. (En español: "Pasen y vean... Imagen y city marketing en las nuevas estrategias urbanas", en Punto de Vista, n 66, abril, 2000).
} 
de la ultra modernidad. Como el capitalismo es también una máquina para generar insignificancia -aunque las cifras de explotación no lo sean - destinada a acumular indefinidamente más de lo mismo, no hay ninguna paradoja sino una coherencia involuntaria en un proyecto de restauración del sentido original de hacer ciudad impulsado por "ventajas" sin ningún significado urbano intrínseco más allá de su equivalencia a buenas oportunidades, aunque indiferentes, en tanto que abren una puerta a la globalización, una puerta estrecha por definición. Esto es, sin duda, uno de los rasgos del urbanismo de última generación: vive al acecho de oportunidades... ipara hacer negocios! Cuando lo que está a la venta es un producto inédito: la propia ciudad, que por lo tanto necesitará adoptar una agresiva política de marketing. Tal y como la propia terminología actual lo indica, estamos frente a políticas de promoción de la imagen (image-making); es decir, orientadas comercialmente (business-oriented), incluso cuando se acuerda (hasta de buena fe) conceder esa visibilidad a individuos o colectivos que aspiran a dicha promoción. Así, uno de los ingredientes de la nueva fórmula (en palabras de dos de los ideólogos más conocidos de este urbanismo, aquello que viene siendo llamado como Planificación Estratégica), es el "consenso público" o incluso en la misma línea de eufemismo, la "voluntad conjunta" que llega a constituir el mortero de esa construcción de la ciudad que a la vez le permite dar "el salto hacia adelante, tanto desde el punto de vista físico como económico, social y cultural"

Gobernantes, burócratas y urbanistas parecen converger en una especie de teorema estándar: que las ciudades se convertirán en protagonistas privilegiados, como la Era de la Información les promete, si y sólo si, están debidamente dotadas con un plan capaz de generar respuestas competitivas a los desafíos de la globalización, inclusive para cada oportunidad de renovación urbana que pueda presentarse como una posible ventaja comparativa a ser creada.

Si nos referimos a la moderna ciudad-máquina, el cambio de postura de los urbanistas no deja de ser sorprendente: cuando un urbanista moderno propone una ciudad según el modelo de la línea de montaje fordista, tiene en mente antes que todo la supuesta racionalidad constructiva de tal proceso y quedaría sinceramente consternado, como de hecho quedaron, si fueran expuestos a la dura verdad de su funcionalidad sistémica, por así decirlo, desde su origen. Hoy en día, lo que podría haber sido causa de un escándalo - la revelación de la mercantilización total de un valor de uso civilizatorio como la ciudad - se convierte en la razón legitimadora invocada ostensiblemente. En 
la actualidad, el urbanismo no viene a corregir, sino a aumentar la crecimiento urbano, para optimizar la competitividad de las ciudades, de hecho, todo el vocabulario que adopta, es claramente empresarial. Se ha intercambiado la máquina de la vida moderna por la máquina de expansión actual, y no soy yo la que lo dice, como se verá en breve.

Volviendo en el tiempo, me gustaría recapitular las principales intervenciones urbanas que están en el origen de este proceso: nada menos que las ciudades - empresas estadounidenses que surgieron en los años setenta, de acuerdo con la clasificación de Peter Hall en su libro Ciudades del Mañana, publicado en 1988. Precisamente, la naturalidad con la que algunos teóricos y urbanistas enfrentan el empuje empresarial causado por el indiscutible triunfo del mercado, hace que el fenómeno que nos ocupa se muestre sin disfraces. Este es el caso de Peter Hall, cuya percepción irreverente nos interesa en más de un punto. Él sugiere que, la ciudad - empresa estadounidense, habría nacido de las cenizas del consenso keynesiano, por una especie de giro desconcertante, en sentido estricto, sin mediación y sin mayores consideraciones:

En los años setenta, el urbanismo cambió totalmente y en los ochenta parecía abocado a la autodestrucción. Daba la sensación de que la planificación convencional y el uso de planes y normas para reglamentar el uso del suelo habían caído en total descredito. En lugar de regular el crecimiento urbano, el urbanista se había dedicado a fomentarlo con todos los recursos que tenía a su alcance. La idea que predominaba era que la ciudad era una máquina de crear riqueza y que la función principal de urbanismo era enrasar la maquinaria. El urbanista se identificó cada vez más con el promotor, su tradicional adversario: el guarda bosques se había convertido en cazador furtivo ${ }^{6}$.

No se podría decir mejor, siendo que el autor no es simpatizante de la izquierda.

No cabe aquí recapitular en detalle los acontecimientos que marcaron, en los años 70, la gran inversión de 30 años de expansión de posguerra, sin la cual, el fracaso de la economía urbana y el posterior colapso de las ciudades permanecería incomprensible. Independientemente del esquema explicativo del largo declive de la economía mundial,

6 Hall. P., de Carvalho, P. (2007). Cidades do Amanhã. São Paulo: Perspectiva, p.407. (En español: Hall. P., Freixa, C., tr. (1996) Las Ciudades de Mañana. Barcelona: Ediciones del Serbal. 
lo cierto es que con el final de la Era de Crecimiento, la planificación urbana, destinada por definición a disciplinarlo, acaba de perder su carácter de figura y evidencia de la racionalidad moderna, convirtiéndose en el blanco favorito de la ofensiva liberalconservadora, políticamente victoriosa a partir de 1979/1980. Falta, sin embargo, la fórmula salvadora que da cuerpo a tal obsesión con el crecimiento, obviamente justificado por la creencia economicista del efecto trickle down ${ }^{7}$ de expansión de la actividad.

Para variar, la receta vino desde los Estados Unidos. Y con ella, otra palabra señuelo, la célebre "renovación urbana" y sus derivados no menos obvios: una "alianza" entre el sector público y la iniciativa privada, encargada a su vez de "apalancar" la inversión privada con fondos públicos, siguiendo la descripción de Peter Hall. Este autor recuerda que el agente clave, el catalizador de este cambio fue James Rouse, un empresario de Baltimore. La "rousificación" Estados Unidos puede ser evaluada por la multiplicación del modelo de "recalificaciones" (una palabra mágica en aquel momento) del Puerto de Baltimore, en el estado de Maryland, (Inner Harbor of Baltimore) y de esquemas similares: el Frente Marítimo de Boston (Boston Waterfront); el Mercado de Quincy (Quincy Market) también en Boston, o por ejemplo el San Francisco Fisherman's Wharf y así sucesivamente. Desde el punto de vista - evidentemente crítico - de David Harvey se trata de fenómenos inseparables de la condición posmoderna ${ }^{8}$. El guión que adopta no es otro que el de la reiteración del "espectáculo urbano": la posmoderna sustitución del espectáculo como una forma de resistencia o acontecimiento popular revolucionario, por el espectáculo como una forma de control social.

Por ejemplo, veamos. En los años 60, el escenario de las ciudades americanas fue invadido por las manifestaciones por los derechos civiles, las manifestaciones contra la guerra en el sudeste asiático y disturbios de todo tipo, sobre todo en los barrios negros, siendo que gran parte del descontento urbano, es bueno no olvidar, giraba en torno a los proyectos "modernos" de vivienda y renovación de equipamientos funcionales típicos, ahora amenazados por disturbios que se estaban volviendo endémicos. Fue entonces cuando, a principios de los años 70, todo este movimiento terminó siendo "tomado por fuerzas muy diferentes y utilizado para fines muy diferentes". Baltimore se convirtió entonces en un resumen ilustrativo de esta evolución del espectáculo urbano. Este es el

\footnotetext{
$7 \quad$ El "efecto de goteo" (en inglés trickle-down effect) es un fenómeno de marketing que afecta a muchos bienes de consumo. Inicialmente, un producto puede ser tan costoso que sólo las personas con poder adquisitivo pueden permitírselo. Con el paso del tiempo, sin embargo, el precio de ese mismo producto caerá hasta que sea suficientemente accesible para el público en general. (Nota de la traductora)

8 Harvey, D. (1992) A Condicao Pos-Moderna: Uma Pesquisa Sobre As Origens Da Mudanca Cultural. São Paulo: Loyola. p. 88-92. Publicado originalmente en inglés en 1989. (En español: Harvey, D., Eguía, M. (1990) La condición de la posmodernidad: investigación sobre los orígenes del cambio cultural. Buenos Aires: Amorrortu).
} 
punto sobre el que quiero llamar la atención: la bien conocida espectacularización del Harbor Place, por no hablar de eventos muy característicos como la Feria de Baltimore, considerada de notable éxito, que acabó concentrando perspicazmente la dimensión más disfrutable de la nueva receta - "la arquitectura del espectáculo, con su sentido de brillo superficial y placer participativo transitorio, de exhibición, de fugacidad y goce". Por supuesto, no sólo por una estetización bastarda sino además por el impacto nulo sobre la pobreza y otros déficits sociales. De este modo se soslayó el contenido de la iniciativa, que debemos recordar, como de hecho lo hace Harvey, de forma breve pero precisa: la necesidad de neutralizar, entre otras cosas, los efectos del asesinato de Martin Luther King, en 1968, que amenazaba la viabilidad de las inversiones - llevó a los líderes locales a buscar un símbolo alrededor del cual construir una idea de "ciudad como una comunidad" en contraposición a la ciudad sitiada, con la que el ciudadano común se enfrentaba en el centro de la ciudad y en sus espacios públicos. Así surgió la Baltimore City Fair con el fin de promover el desarrollo urbano, la celebración de la "proximidad" y la diversidad étnica de la ciudad; el siguiente paso se tradujo en la "comercialización institucionalizada de un espectáculo más o menos permanente con la construcción del Harbor Place", recordando que los propios grupos étnicos comenzaron aprovechando "la venta de la etnicidad" a falta de mercado para su fuerza de trabajo. Hasta aquí - para seguir con nuestro argumento - Harvey y el panorama general de la condición posmoderna, igualmente recalcado por Peter Hall, agregaría que tal creación deliberada de una etapa cuyo prototipo había sido la "rousificación" de Boston y Baltimore. En última instancia, la comprensión de la intervención urbana como un proceso de producción de sitios o locales de éxito era el registro y la garantía espectacular de que - en palabras del autor - "una nueva y radical élite de empresarios se hizo cargo de la ciudad, y organizó una coalición que, con habilidad, obtuvo el apoyo público y supo combinar la ayuda federal con el dinero privado para realizar proyectos comerciales a gran escala." 9 .

En pocas palabras, la idea de la ciudad como growth machine (una máquina de crecimiento) (aquí se utiliza una expresión puesta en circulación en los Estados Unidos, por Harvey Molotch en el 1976, de la cual la ciudad-empresa de Peter Hall es sólo una variante $)^{10}$ se puede resumir de la siguiente manera: las coaliciones de élite centradas en los bienes raíces y sus derivados, además de una legión de lacayos profesionales

\footnotetext{
$9 \quad$ Peter Hall, op.cit., p.413.

10 The City as a Growth Machine: Toward a Political Economy of Place fue publicado por primera American Journal of Sociology, Vol. 82, No. 2 (Sep., 1976), pp. 309-332. Más aún, un año antes de su libro sobre Las Ciudades del Mañana, la comunicación de Harvey Molotch había sido tomada en su totalidad en un libro en co-autoría con John Logan, Urban Fortunes - The Political Economy of Place, University California Press, 1987; véase también Jonas y Wilson (eds.), The Urban Growth Machine, Critical Perspectives Two Decades Later, New York: State University of New York Press, 1999.
} 
en un amplio espectro de negocios resultantes de las posibilidades económicas de los lugares, se ajustan a las políticas urbanas, en la medida en que les dan rienda suelta a su propósito de expandir la economía local y aumentar la riqueza. La fabricación de consensos sobre un crecimiento a cualquier precio - como la esencia misma de todo lugar - se convierte en la pieza clave de una situación de movilización competitiva permanente para la batalla de suma cero con las ciudades participantes. Una fábrica por excelencia de ideologías, por lo tanto: del territorio, la comunidad, la civilidad, y así sucesivamente. En el corazón de estas coaliciones, la clase adinerada de siempre, hoy de nuevo a la vanguardia de los "movimientos urbanos": los desarrolladores, corredores, banqueros, etc., anclados a un séquito de apoyo también interesado y poderoso como los medios de comunicación, políticos, universidades, empresas deportivas, cámaras de comercio y, por último, nuestros dos personajes de esta trama de estrategias: los urbanistas y los promotores culturales.

Con el afianzamiento de la hegemonía estadounidense, comúnmente conocida como "globalización", el modelo de ciudad como "máquina de crecimiento" se generalizó con el pretexto de dar respuesta a las mismas presiones competitivas en torno al capital escaso y nómada, aunque en verdad atendiendo los imperativos (políticos) de la cultura anglosajona de negocios"1, ("like business") sino para los negocios ("for business”) (también de acuerdo con Harvey Molotch). O más bien, es como si la transnacionalización productiva y financiera, al contrario de lo que uno podría predecir y en función del acentuado localismo de las máquinas urbanas de crecimiento, acabase confiriendo a la ciudad - precisamente debido a la redirección de los Estados Nacionales cada vez más vaciados y deslegitimados socialmente por su estrecha simbiosis con el públicamente (y descaradamente) "impulsado" mundo de los negocios- una segunda juventud cosmopolita por medio de coaliciones urbanas pro-crecimiento.

Finalmente, no se trata de constatar la colonización de la vida cultural (que por cierto nació colonizada como su nombre lo indica) por la ciudad como una máquina de crecimiento, sino más bien, la operación inversa: como el nuevo combustible sin el cual la coalición no fabricaría los consensos que necesita. Aunque no es exactamente la cultura el foco de análisis de Molotch, si lo es el conjunto de condiciones que pone en movimiento la máquina urbana de "aumentar la plusvalía", y que son indicados como ingredientes indispensables para los buenos negocios - quién diría, con tanta antelación? -: el "orgullo cívico" de los habitantes del lugar y el "patriotismo de 
masas" (retomados literalmente por Borja y Castells en Hábitat II como la receta de la "Planificación Estratégica") ${ }^{12}$ - que a diferencia de los teóricos (defensores o críticos) de la ciudad-empresa que vieron una convergencia rentable, los "estrategas catalanes" pretendieron que fuera una "articulación" concertada ... y por lo tanto capaz de inducir una nueva ola de civilidad... de la malentendida relación ambigua entre la política real y la epidermis cultural.

De hecho, la máquina de crecimiento urbano no es más que una máquina ideológica impulsada por aquellos que administran la construcción, tanto física como de los recursos ideológicos, capaces de impulsar el desarrollo dentro y a través de los "lugares" de la ciudad, acertadamente llamados urban imagineers. En estas circunstancias, no es de extrañar que el arquitecto-urbanista se haya convertido en uno de los operadores claves de esta máquina, que reúne en un solo personaje al manager (el planificadorempresario identificado por Peter Hall) y al "mediador cultural" (señalado por primera vez por Bourdieu) proveedor para un segmento de la clase productora de bienes y servicios simbólicos, cuya trayectoria es ascendente y reveladora del actual culturalismo del mercado. Intermediario (mediador) y empresario cultural, al mismo tiempo que uno de los principales agentes de la gentrificación, cuyo carácter de clase o gentry en inglés (nobleza) queda vergonzosamente expuesto. De ahí la mala fama que acompaña habitualmente el empleo vergonzoso de la palabra, por lo mismo se oculta tras el recurso constante del eufemismo: revitalización, rehabilitación, revaloración, reciclaje, promoción, recualificación, incluso renacimiento, y así sucesivamente, apenas encubriendo, por el contrario, el sentido original de la invasión y reconquista, inherente al retorno de los estratos sociales acomodados al corazón de las ciudades.

Lo que estoy queriendo sugerir es que la planificación llamada estratégica puede no ser más que otro eufemismo para gentrificación. Aunque no sean exactamente la misma cosa, tal vez sea su apoteosis: una ciudad estratégicamente planificada de la A a la $\mathrm{Z}$ sería, en definitiva, una ciudad enteramente gentrificada. Se abrirá un paréntesis (con algunos ejemplos) sobre este tema que se ha convertido en uno de los puntos clave en la explicación culturalista de la expoliación urbana porque, después de todo, lo que importa en todo esto es siempre determinar quién sale y quién entra, aunque en esta

$12 \quad$ Op.cit., cap.5. 
ocasión se trate de una apropiación del espacio legitimada por el upgrading cultural.

El más conocido y repetido modelo de esta asociación hegemónica entre especuladores, políticos y urban imagineers no por casualidad se encuentra en Nueva York en el proceso de gentrificación del SoHo, en un principio, fomentando el reciclaje de lofts para la comunidad local de artistas; esa es la novedad de la articulación del capital y de la cultura en la remodelación de la ciudad, destacada por el estudio pionero de Sharon Zukin $^{13}$. Para variar - de una manera ejemplar desde los años 70 - se rehabilitó un área devastada por medio de una operación "concertada" (como dirían los ideólogos catalanes) de recalificación de los espacios abandonados de las antiguas fábricas, convertidos en galerías o incluso residencias de artistas, boutiques, restaurantes sofisticados, etc., con la consecuente migración forzada de los antiguos residentes y la conversión de los pocos propietarios restantes, disfrazados de intermediarios de grandes negocios inmobiliarios. Nuevos patrones de gusto y consumo difundían la sensación reconfortante de que una vida de artista, esta vez reconciliada con la sociedad, podría ser el atributo de una nueva vanguardia de la burguesía; por supuesto, un conjunto de transgresiones sistemáticas de la legislación con apenas disimulado consentimiento de la administración local.

A continuación, el embrión de un cambio emblemático: en la medida en que la cultura pasaba a ser el principal negocio de las ciudades en vías de gentrificación, fue cada vez más evidente para los agentes envueltos en la operación que, era ella, la cultura, uno de los más poderosos medios de control urbano en el actual momento de la reestructuración de la dominación mundial. Más o menos de la siguiente manera, como se puede leer en un estudio posterior de Sharon Zukin acerca de las estrategias culturales de desarrollo urbano, cuya esencia nuevamente reside en la propagación de la imagen de un centro de innovación, cualquiera que sea, de servicios financieros de máxima seguridad para las personas solventes ${ }^{14}$. Es necesario distinguir, por encima de la base formada por los factores económicos clásicos sobre los que se construye una ciudad - tierra, trabajo y capital - al menos tres capas de intercambios desiguales, y en este caso, intercambios "simbólicos". La primera de ellas consiste en la manipulación de los lenguajes simbólicos de exclusión y de habilitación (entitlement): la "imagen" de una ciudad, o la manera por la cual esta se deja, por así decirlo, manosear; su aspecto "táctil", podemos añadir, refleja las decisiones sobre qué y quien puede ser visible o no,

13 Loft Living, Brunswick, Rutgers University Press, 1989 (publicado por primera vez en 1982). David Harvey le dio el debido crédito al escribir el prólogo de la edición británica de 1988. Véase también en el mismo Harvey otro comentario al respecto en A Condição Pós-Moderna, ed.cit., p.82.

14 Cultures of Cities, Cambridge, Blackwell, 1995, cap.1 
las banales decisiones sobre el orden y el desorden, lo que lleva a una estetización del poder, en la cual el diseño arquitectónico es uno de los instrumentos más ostentosos. En la segunda capa, nos enfrentamos de nuevo, no por casualidad, con la máquina de Molotch: en donde la economía simbólica de la ciudad también es controlada por la habilidad de los "place entrepeneurs" (los cuales fueron los últimos en unirse hoy a los ideólogos del "lugar") en su trato con los símbolos de crecimiento, y su promesa de empleos y negocios. Por último, el sector más tradicional, actualmente reactivado con el ritmo acelerado del capitalismo americano, en alianza con los círculos empresariales y los "abogados de la ciudad" que, gracias a una combinación eficiente de patrocinio y orgullo cívico, cimentado por el deseo de presentarse a sí mismo como un nuevo patriarcado, se encargará de hacer que se multipliquen los museos grandilocuentes, parques y complejos arquitectónicos para garantizar por derecho que se está entrando en una "world-class-city". Es esta simbiosis de imagen y producto ${ }^{15}$, lo que caracteriza a la ciudad-empresa cultural que persigue la actual generación de urbanistas.

No sería el momento ahora de compilar los innumerables ejemplos neoyorquinos de gentrificación estratégica, si es que se puede hablar así, a pesar de que se trate de eso. El principio de la máquina de crecimiento cultural no varía demasiado, como se podrá verificar con la famosa recalificación del Battery Park $^{16}$, bajo el guión de siempre: concebida a mediados de los años 60 como una nueva zona habitacional de Manhattan, diseñada en principio para varios estratos sociales, fue poco a poco transformándose en un vasto proyecto de gentrificación impulsado por una sucesión de crisis (algunas fabricadas) y por las medidas gubernamentales de "ayuda", como su habitual procesión de comercio chic y equipamientos culturales, incluyendo un verdadero festival de arte público (o lo que actualmente se asume como tal), los cuales consagrarían la unión entre arte y urbanismo, debidamente enmarcada por una fantasía kitsch, según la cual el encuentro de tierra y agua que allí se había celebrado, descendía de la misma noble estirpe de Venecia, Constantinopla y San Petersburgo ${ }^{17}$.

Todavía otra novedad: la gentrificación de Harlem a partir de la demolición de varios de sus edificios, especialmente en los distritos históricos de Hamilton Heighs y Sugar

\footnotetext{
15 En la fórmula de Sharon Zukin, op.cit

Battery Park City es anunciado como uno de los nuevos barrios urbanos más exitosos en el mundo y como un proyecto de renovación urbana exitoso y modélico. Está situado en el extremo sur de la isla de Manhattan, frente al Puerto de Nueva York, sobre un área que antes fue ocupada por los deteriorados muelles del río Hudson. Incluye además del parque público, edificios de apartamentos, como el Gateway Plaza, primer complejo residencial construido en Battery Park en 1983; edificios corporativos como el complejo World Financial Center (actualmente Brookfield Place) construido en 1988 y edificios comerciales. (Nota de la traductora).

17 Cf. Rosalyn Deutsche, Evictions, Cambridge, MIT, 1996, pp.79-93.
} 
Hill; es decir, una vez más, lo que es obvio: en nombre de una memoria reactivada y una identidad reconquistada, no cabe preguntar por el destino de los actuales residentes que seguramente no pueden costear el monto del alquiler de habitaciones y apartamentos que superan los $\$ 2.000$ al mes.

Con estos pocos ejemplos, sin embargo arquetípicos, es el momento de completar el razonamiento, observando algo aparentemente trivial, pero que en realidad hace tiempo que dejó de serlo: el hecho de que las áreas gentrificadas sean zonas altamente vigiladas, que de acuerdo a la gramática estetizante antes mencionada. Poco existe sobre el tema de las "actividades" que son restringidas, desde el habitar a la simple permanencia en parques recalificados. Esta medida es, el último y más simple mecanismo de subordinación de un espacio público para el control privado, como si fuera poco, en la forma de una ONG creada ad hoc por la coalición local de rehabilitadores urbanos: se redibuja el lugar, se programan eventos culturales, se abre un café o algo igualmente chic, completando el servicio con una pequeña horda de guardias de seguridad. Y así sucesivamente, con intervenciones cada vez más complejas, hasta lograr que toda la ciudad que importa sea un enclave propiamente global. Llegamos, por fin, a lo que se ha llamado la "estetización del miedo"18, y que se convertirá en el detonante secreto del repentino interés manifestado por las elites globales por el espacio público, sobre el cual, estas, se pondrán sintomáticamente a hablar profusamente: no hay mecenas que se aprecie que no patrocine alguna área pública, con el celo ancestral demandado por esta nueva afluencia de enclaves, como en los tiempos de la acumulación primitiva.

En este punto es bueno no perder de vista el origen militar de la palabra estrategia, que de la esfera semántica de guerra económica fue trasplantada, con precisión involuntaria, por un urbanismo que al menos confiesa necesitar de adversarios, fácilmente identificables. Así que creo que es el momento de incluir la "ciudad revanchista", descrita por Neil Smith ${ }^{19}$, ante la gentrificación estratégica de la que estamos hablando. La designación no debe sorprender en la era de la revancha del Capital en todos los frentes - cuya magnitud puede ser explicada por el Gran Miedo que siguió a la explosión de los años 60/70. En el ámbito propiamente urbano, la revancha contra los trabajadores precarizados, inmigrantes, personas sin hogar, etc., en fin, todo tipo de clase peligrosa que pudiera amenazar el sueño de los otrora vencedores. Por ciudad revanchista, Neil Smith entiende más específicamente la reanudación agresiva de la gentrificación después de los grandes fracasos de los años 80, pero sobre todo como una 
reacción a la decadencia urbana causada por la primera ola de desregulación y recortes de los programas sociales. No es difícil percibir, sin embargo, que el revanchismo que anima sin disfraz la gentrificación estratégica, es una expresión de una escalada más extensa y profunda en la guerra social contemporánea, cristalizada, entre otras condiciones, por la actual hegemonía global, una especie de nuevo sentido común penal - la criminalización de la pobreza y la normalización del trabajo precario - cuya manifestación urbana también puede ser identificada como una suerte de principio de la inviolabilidad del espacio público, por eso mismo sometido a una estricta vigilancia privada $^{20}$. Una "nueva doctrina punitiva" alimenta la progresiva sustitución del Estado de Bienestar por el Estado Penal ( $0,5 \%$ de la población adulta estadounidense se encuentra bajo vigilancia penal, y de ella, el $80 \%$ son negros), a su vez monitoreado por el complejo industrial carcelario, otra rama muy próspera en el capítulo de la privatización. Es así como la estetización cultural del miedo es inducida por la actual fase de gentrificación. Ahora, otra ironía, esta vez semántica, pero en sintonía con la disección que estamos siguiendo, consiste en bautizar en el nombre de la civilidad enfáticamente cultural - esa marea punitiva que acoge cada oportunidad de penetración del nuevo Estado Penal, como un gesto de audacia cívica contra el debilitamiento de la voluntad política de los gobernantes. No hay dispositivo de seguridad que no pase luego a representar una fuerza civilizatoria, como la "tolerancia cero" del ex alcalde de Nueva York Rudolph Giuliani (1994 - 2002), para dar el ejemplo más reciente. Así, según el conocido administrador de Nueva York, en "una ciudad civilizada, las calles no son un lugar para dormir, las personas deben utilizar las habitaciones".

No es sorprendente que en estas circunstancias, la jerga de civilidad haya impregnado el conjunto de nuevas estrategias urbanas, pues al final, ambos tienen el mismo origen en la gestión empresarial. Según el enfoque de civismo de Giuliani, podemos imaginar lo que está pasando hoy en día al interior de una ciudad-empresa. Y por extensión, en los espacios gentrificados de una ciudad-empresa cultural, que debería entonces ser descrita desde otro ángulo: no sólo como una ciudad-negocio, sino también como una ciudad "pulida" en todos sus engranajes - desde una dependienta de boutique a un transeúnte benevolente, como si se viviera dentro de una ONG de asfalto - como una empresa regida por un libreto al servicio del cliente, como en cualquier restaurante de fast food. Las ciudades globales ciertamente causan la mejor de las impresiones, razón de más para replicarse el modelo de enclaves en la periferia. 
Por estas y otras consideraciones, cuando se habla hoy en día, indirecta o directamente, de "hacer ciudad", semejante eufemismo bien merece la pregunta: ¿quién realmente "hace ciudad"? La respuesta, al menos a partir de los años 90, parece inequívoca: naturalmente, las grandes empresas, con las mediaciones habituales, por supuesto. Por lo tanto, el mismo paisaje en todas partes, o más bien, sin contar los simulacros en las periferias, los mismos paisajes de poder descritos por Sharon Zukin en las ciudades globales como Nueva York y Londres ${ }^{21}$. No hay nada de sorprendente en esto, pues el desarrollo de las áreas centrales de estas dos ciudades, no por casualidad, cayeron en manos de las mismas instituciones financieras, los mismos mega desarrolladores de bienes raíces, de las mismas oficinas del star system, que a su vez prepararon el terreno a pedido de las sedes multinacionales de siempre. Y así sucesivamente, van las grandes corporaciones multinacionales, tratando de persuadirnos de que los verdaderos protagonistas de la escena mundial son -quien diría- las ciudades, o más bien, las ciudades cuya configuración se propicia por la valoración de activos que más interesa a tales firmas en el presente estado de transnacionalización productiva. La rentabilidad y el patrimonio arquitectónico y cultural se dan la mano en este proceso de revalorización urbana - siempre, y por supuesto, en nombre de una supuesta civilidad. Y para entrar en este universo de negocios, la contraseña más prestigiosa - a qué punto llegamos! (de sofisticación?) - es la cultura. Esta nueva tendencia del mundo fashion, la sociedad afluente de los altos servicios a los que aspiran.

Pero no se trata de una cultura cualquiera, aquí interesa subrayar el momento crucial en cuanto a este último giro urbanístico: se trata de una cultura - la industria de la conciencia en las grandes fachadas, pasando por las gentrificaciones pertinentes que paradójicamente (o no?) es respaldada por el aura libertaria de resistencia antiproductivista cuya génesis se remonta a los movimientos de los años 60. Por lo tanto no gurda ninguna relación con lo que se entendía por cultura en el ciclo histórico anterior, ese breve intervalo de la Era de Crecimiento de la posguerra, por no mencionar por supuesto, la vieja esfera autónoma y trascendente de la extinta Edad Liberal-burguesa.

Hubo así una metamorfosis de lo "cultural", cuyo post-materialismo, al principio reactivo, estaba convirtiéndose en pro-activo, para no decir cooperativo, en la medida en que se estetizaba y se concentraba en los valores expresivos de un orden social que alegaba a su favor haber destronado la primacía de las relaciones de producción 
en nombre de las relaciones de "seducción", siendo aclamada como la Era del Vacío la que iniciaba. Si no me equivoco, ni siquiera fue necesario esperar por las grandes desregulaciones del período siguiente, comenzando por la flexibilización de la rigidez fordista, para acelerar la mutación indolora de la cultura-libertaria, empeñada en recuperar la riqueza simbólica de las formas urbanas (según la formulación de Léon Krier), en el embrión de los futuros sembradores de cebos culturales para el capital , para los cuales la monotonía funcional del Modernismo con seguridad había creado una demanda reprimida.

Ciertamente, si todo parece haber comenzado en los Estados Unidos, al atravesar el Atlántico, la máquina de crecimiento fue aceitada, especialmente en lo que respecta al énfasis superlativo de la cultura y la glamorosa convergencia entre alta cultura y los grandes negocios. De esta unión nacía el mito bifronte del gran proyecto de ciudadcollage, del cual, el París de François Mitterand es el ejemplo máximo y seguramente (o sin duda) el punto de inflexión. Todo estaba allí, en aquellas medidas de regulación flexible de lo urbano y en la expansión de la industria cultural que incorporaría, la cultura de los museos y sus arrogantes adyacencias intelectuales, al capitalismo de imágenes y de ennoblecimiento arquitectónico del mundo de los negocios al que corresponde la mitología urbanizadora del sector terciario, sin el que no es posible aspirar al status de ciudad global ${ }^{22}$.

Después de París, pasando por Barcelona hasta la nueva capital de la Alemania unificada, un sinnúmero de ciudades no han hecho sino aplicar la fórmula de la ciudadempresa cultural. Una combinación, por así decirlo, del modelo liberal-americano y el social-progresista europeo. En resumen, sucede que estamos ante algo así como un pensamiento único - con el que se casan los intereses económicos de la cultura y de las reivindicaciones culturales de control económico - que rodea las ciudades que compiten por los escasos fondos en el sistema mundial y, por eso mismo, comparten por defecto las preferencias políticas e ideológicas de los administradores de turno. 


\section{Referencias}

ARANTES, Otília, VAINER, Carlos, MARICATO, Ermínia. A Cidade do Pensamento Único. Desmanchando Consensos, Petrópolis, Vozes, 200o. (Título en español: La Ciudad del Pensamiento Único. Desmontando Consensos.)

ARANTES, Otília. O lugar da Arquitetura depois dos Modernos, São Paulo, EDUSP, 1993. (Título en español: El lugar de la Arquitectura después de los Modernos)

Urbanismo em fim de linha, São Paulo, EDUSP, 1999 (Título en español: Urbanismo al final de línea)

"Vendo Cidades", en Veredas no 36, Rio de Janeiro, diciembre de 1998 (Título en español: Visualizando Ciudades)

BORJA e CASTELLS. Local y Global, Madrid, Taurus, 1997

DEUTSCHE, Rosalyn. Evictions, Cambridge, MIT, 1996

GRAY, John, Falso Amanhecer - Os Equívocos do Capitalismo Global, São Paulo, Record, 1999 (Título en español: Falso Amanecer: Los Engaños del Capitalismo Global. Paidós Ibérica, 2000).

HALl, Peter, Cidades do Amanhã, São Paulo, Perspectiva, 1995 (Título en español: Ciudades del Mañana: Historia del Urbanismo en el siglo XX, Ediciones del Serbal, 1996)

HARVEY, David, Condição Pós-Moderna, São Paulo, Loyola, 1992 (Título en español: La Condición de la Posmodernidad: Investigación sobre los Orígenes del Cambio Cultural. Buenos Aires: Amorrortu Editores, 1990).

INDOVINA, Francesco. "Os Grandes Acontecimentos e a Cidade Ocasional”, en Lisbon: World Expo 98. Projects, Blau, 1996 (Título en español: Los Grandes Eventos y la Ciudad Ocasional)

JONAS e WILSON (orgs.), The Urban Growth Machine, Critical Perspectives Two Decades Later, New York, State University of New York Press, 1999. (Título en español: La Máquina del Crecimiento Urbano, Perspectivas Críticas Dos Décadas Después) 
LOGAN e MOLOTCH, Urban Fortunes - The Political Economy of Place, University California Press, 1987 (En español: Fortunas Urbanas - La Economía Política de Lugar)

SMITH, Neil, The New Urban Frontier: Gentrification and the Revanchist City. Londres, Routledge, 1996. (Título en español: La Nueva Frontera Urbana: Ciudad Revanchista y Gentrificación, Madrid: Traficantes de Sueños, 2012).

WACQUANT, Loïc, “Ce vent punitif qui vient d'Amérique”, en Le Monde Diplomatique, abril, 1999. (Título en español: Este viento punitivo que viene de América)

ZUKIN, Sharon, Landscapes of Power. From Detroit to Disney World, University of California Press, 1991. (Título en español: Paisajes del Poder)

Loft Living, Culture and Capital in Urban Change, News Brunswick, Rutgers University Press, 1989. (Título en español: Loft Living, Cultura y Capital en el Cambio Urbano)

The Cultures of Cities, Cambridge, Blackwell, 1995 (Título en español: La cultura de las ciudades) 
Este artículo forma parte de:

\section{REVISTARQUIS}

Para más información, artículos, e instructivo de publicación, visite:

www.arquis.ucr.ac.cr/revistarquis.html 